\title{
Adalimumab in the management of Behçet's disease
}

\author{
This article was published in the following Dove Press journal: \\ Therapeutics and Clinical Risk Management \\ 13 April 2015 \\ Number of times this article has been viewed
}

\author{
Atsuhisa Ueda \\ Mitsuhiro Takeno \\ Yoshiaki Ishigatsubo \\ Department of Internal Medicine and \\ Clinical Immunology, Graduate School \\ of Medicine, Yokohama City University, \\ Yokohama, Japan
}

\begin{abstract}
Behçet's disease (BD) is a relapsing, systemic, inflammatory disorder that affects various organ systems. Most of the manifestations of BD are self-limiting, but ocular attacks are an exception. Gastrointestinal tract, central nervous system, and cardiovascular system manifestations are relatively infrequent but may be resistant to conventional immunosuppressive treatment and therefore life-threatening. Tumor necrosis factor alpha antagonists are increasingly being used in patients whose BD is inadequately controlled by standard immunosuppressive regimens. Most of the current experience regarding the treatment of refractory BD involves the use of infliximab; however, adalimumab has also been successfully used in cases of BD refractory to both conventional therapy and infliximab. Compared with infliximab, adalimumab offers several other advantages, such as the ability to self-administer at home, better patient compliance, and an improved side effect profile. Here, we review clinical experience of the use of adalimumab to treat the serious manifestations of BD. Adalimumab is a promising drug for the treatment of $\mathrm{BD}$, and its randomized, prospective study in a large number of patients is warranted to fully determine its efficacy in the refractory BD setting.
\end{abstract}

Keywords: adalimumab, Behçet's disease, intestinal BD, infliximab, ocular lesion, central nervous system

\section{Introduction}

Behçet's disease (BD) is a chronic, systemic, inflammatory disorder characterized by mucocutaneous, ocular, articular, vascular, gastrointestinal, and central nervous system manifestations. ${ }^{1} \mathrm{BD}$ is prevalent in countries along the historical Silk Road, from the Mediterranean region to the Far East, where it is often associated with the major histocompatibility complex antigen allele $H L A-B 51 .{ }^{1}$ The incidence of $\mathrm{BD}$ is roughly 1 in 1,000 people in Turkey, 1.5 in 10,000 people in Japan, and 1 in 10,000 in other Silk Road areas, whereas it is only 1 in 1,000,000 in the UK and North America. ${ }^{1-3}$ The clinical diagnosis of BD is based on the International Study Group for BD's classification criteria, which include the presence of recurrent oral ulceration plus at least any two of genital ulceration, ocular lesion, typical skin lesion, or positive pathergy (skin hyper-reactivity) test. ${ }^{4}$ Diagnostic criteria have also been published by the BD Research Committee of Japan. ${ }^{5}$ Recently, the International Team for the Revision of the International Criteria for BD proposed a novel, point-based assessment for the diagnosis and classification of BD; in this assessment the presence of ocular lesions, oral aphthosis, and genital aphthosis are each assigned two points, and skin lesions, central nervous system involvement, vascular manifestations, and positive pathergy test are each assigned one point; a patient scoring $\geq 4$ points is diagnosed as having $\mathrm{BD}{ }^{6}$
Correspondence: Yoshiaki Ishigatsubo Department of Internal Medicine and Clinical Immunology, Graduate School of Medicine, Yokohama City University, 3-9 Fukuura, Kanazawa-ku, Yokohama 236-0004, Japan

$\mathrm{Tel}+8 \mid 457872630$

Fax +8 I 457863444

Email ishigats@med.yokohama-cu.ac.jp
Therapeutics and Clinical Risk Management 20I5:I I 6II-6I9

submit your manuscript | www.dovepress.cor

Dovepress

http://dx.doi.org/10.2147/TCRM.S56163 (c) (1) (5) 2015 Ueda et al. This work is published by Dove Medical Press Limited, and licensed under Creative Commons Attribution - Non Commercial (unported, v3.0) BY NC License. The full terms of the License are available at http://creativecommons.org/licenses/ly-nc/3.0/. Non-commercial uses of the work are permitted without any further how to request permission may be found at: http://www.dovepress.com/permissions.php 


\section{Pathogenesis}

Unique geographic distribution of $\mathrm{BD}$ patients along the historical Silk Road area suggests that genetic factors play a critical role in the pathogenesis of this disease. Recently, several genome-wide association studies have been reported. Japanese and US groups (Remmers et $\mathrm{al}^{7}$ and Mizuki et $\mathrm{al}^{8}$ ) have revealed associations with BD at the HLA class I, IL10, and $I L 23 R$ loci. Furthermore, Kirino et al ${ }^{9}$ have reported associations with BD at the CCR1, STAT4, KLRC4, and ERAP1 loci, which encode molecules that play important roles in T-cell-mediated immunoregulation (especially Th1-, Th2-, and Th17-mediated immunoregulation), activation of natural killer cells, chemotaxis, and proper peptide presentation by major histocompatibility complex class I molecules.

Although the etiology of BD remains unclear, hyperfunction of neutrophils, which results in tissue injury and vasculitis, is a well-characterized hallmark of the disease. Furthermore, the clonal expansion of T-cells, which autoreact with heat shock protein 60 , has been reported in BD patients. ${ }^{10}$ Since heat shock protein 60 is highly homologous with bacterial heat shock protein 65 , there may be a relationship between bacterial infection and the pathogenesis of BD. ${ }^{11}$ Indeed, the incidence of BD among Turkish patients living in West Berlin has been reported to be 2.26 in 100,000, which is much lower than that reported in Turkey $\left(1\right.$ in 1,000), ${ }^{12}$ strongly suggesting that environmental factors play a key role in the pathogenesis of $\mathrm{BD}$.

We previously reported that the numbers of peripheral blood cells spontaneously secreting interferon- $\gamma$, interleukin 12 , and TNF- $\alpha$ were significantly increased in patients with active BD. ${ }^{13}$ TNF- $\alpha$ has been shown to play an important role in the pathogenesis of BD. For example, increased expression of TNF- $\alpha$ by $\gamma \delta$ T-cells and monocytes in the peripheral blood has been confirmed in patients with active $\mathrm{BD},{ }^{14}$ and increased expression of TNF- $\alpha$ mRNA has been observed in the ulcerative lesions of patients with active intestinal BD, which was diminished after treatment. These reports had suggested that TNF- $\alpha$ is a possible therapeutic target in $\mathrm{BD}$.

\section{Adalimumab for the treatment of Behçet's uveitis}

Ocular manifestations affect $60 \%-80 \%$ of all BD patients and often result in severe visual impairment. In the clinical data of 1,465 patients with ocular lesions, most of the patients had bilateral, recurrent intraocular inflammation, and poor visual acuity was reported in $18.9 \%$ of women and $24.8 \%$ of men. ${ }^{15}$ In addition, patients with poor vision were more frequently reported from India, Iraq, and Japan than from the other countries. ${ }^{15}$

Various systemic corticosteroids and immunosuppressive drugs (eg, colchicine, cyclosporine A, cyclophosphamide, methotrexate, and azathioprine) have been used as conventional therapy for the treatment of $\mathrm{BD}$; however, these therapies have been shown not to reduce disease activity. ${ }^{16}$ The recent development of biological therapies, though, has revolutionized the treatment of BD. For example, infliximab is a chimeric IgG1 monoclonal antibody (mouse and human) that disrupts inflammatory immunoregulation by binding to TNF- $\alpha$, thus preventing it from binding to its receptor. Many small, open-label prospective studies have demonstrated that infliximab is efficacious for treating Behçet's uveitis. ${ }^{17-23}$ For example, Okada et $\mathrm{al}^{17}$ have reported favorable results from a multicenter prospective study of infliximab use in $63 \mathrm{BD}$ patients with refractory uveoretinitis. Before the start of infliximab treatment, 52 patients were diagnosed with severe uveoretinitis and 11 were diagnosed with moderate uveoretinitis. An efficacy analysis after 1 year showed that uveoretinitis had improved in $69 \%$ of patients, had somewhat improved in $23 \%$, was unchanged in $8 \%$, and had worsened in none.

Furthermore, Takeuchi et a ${ }^{18}$ have evaluated the longterm efficacy of infliximab for the treatment of Behçet's uveitis in 164 consecutive patients who were treated for at least 1 year. The percentage of patients receiving concomitant cyclosporine A was reduced from $44.5 \%$ to $25.6 \%$, and that of patients receiving concomitant corticosteroids from $39.6 \%$ to $29.3 \%$. Infliximab treatment was continued in $85 \%$ of patients after observation period but was discontinued in $15 \%$ because of adverse effects or insufficient efficacy.

Recently, the American Uveitis Society proposed new recommendations for the use of anti-TNF- $\alpha$ biological agents in patients with ocular inflammatory disorders. In these recommendations, infliximab and adalimumab are considered first-line corticosteroid-sparing therapies for the treatment of ocular manifestations of BD. ${ }^{24}$

Adalimumab is a completely humanized IgG1 monoclonal anti-TNF- $\alpha$ antibody that binds to TNF- $\alpha$ (free and membrane-bound) and prevents it from binding to its receptors. It was the third TNF- $\alpha$ inhibitor, after infliximab and etanercept, to be approved by the US Food and Drug Administration for the treatment of rheumatoid arthritis, and it has since been approved for a further six indications: juvenile idiopathic arthritis, psoriatic arthritis, ankylosing spondylitis, Crohn's disease, ulcerative colitis, and psoriasis.

Since the overall patient population treated with adalimumab is smaller than that treated with infliximab, 
there are few data available on the comparative efficacies of infliximab and adalimumab for the treatment of ocular manifestations of BD. However, four prospective openlabel studies, ${ }^{25-28}$ two retrospective analyses, and five case reports have been published (Table 1). ${ }^{29-35}$ Of 47 patients with Behçet's uveitis treated with adalimumab, 42 (89\%) showed a satisfactory response, 2 (4\%) showed a partial response, and $3(6 \%)$ showed no response. Twenty-five of these patients were treated with infliximab before subcutaneous adalimumab. In 18 of these 25 patients, infliximab was stopped because of insufficient efficacy or an adverse reaction to the infusion. Also, patients who are switched to anti-infliximab antibody are prone to develop de novo antiadalimumab antibody (immunogenicity) ${ }^{36}$ Only two of these 18 patients did not respond to adalimumab therapy; the other 16 had good clinical courses.

In Japan, adalimumab is less frequently used for BD uveitis since infliximab has been approved for the treatment of refractory BD uveitis in 2007. Nonetheless, adalimumab shows efficacy even in some patients with infliximabresistant uveitis. ${ }^{34}$

\section{Adalimumab and alternative therapies for the treatment of intestinal BD}

Intestinal $\mathrm{BD}$ is characterized by intestinal ulcerations and gastrointestinal symptoms and occurs in 3\%-16\% of all BD patients. It typically presents as round or oval ulcers in the ileocecum, and the most common gastrointestinal symptoms are abdominal pain, diarrhea, and bleeding. Esophageal involvement is rare, but ulceration can occur anywhere throughout the gastrointestinal tract. As with the overall prevalence of $\mathrm{BD}$, the prevalence of intestinal BD also varies by region: in studies conducted in Turkey and Saudi Arabia, 1\% (total, 272 patients) ${ }^{37}$ and 4\% (total, 119 patients) $)^{38}$ of DB patients, respectively, had gastrointestinal involvement, whereas in Taiwan, 32\% (total, 22 patients) had gastrointestinal involvement. ${ }^{39}$ High prevalence of intestinal $\mathrm{BD}$ has also been reported among BD populations in Japan and the UK. ${ }^{40}$

The severity of intestinal BD is usually assessed by taking into account the systemic symptoms present, the results of a physical examination of the abdomen, estimated ulcer depth, and the presence of intestinal complications, increased inflammatory mediators, or anemia. Crohn's Disease Activity Index can be applicable for intestinal BD, because of similarity of clinical manifestations and therapeutic strategies between the both diseases. A Korean group (Cheon et $\mathrm{al}^{41}$ ) has also proposed a novel disease activity index for intestinal BD.

Conventional therapy for the treatment of intestinal BD includes the use of corticosteroids and immunosuppressants; however, gastrointestinal lesions, which can sometimes cause life-threatening comorbidities such as intestinal perforation and acute intestinal bleeding, are often refractory to these therapies.

The second edition of consensus statements for the diagnosis and management of intestinal BD was recently published by the BD Research Committee of Japan. In this publication, corticosteroids are the recommended induction therapy for patients with severe intestinal manifestations of BD. ${ }^{42}$ However, adalimumab or infliximab may also be considered as induction therapy. In patients with mild to moderate disease activity, 5-aminosalicylic acid (5-ASA) may also be effective as induction therapy.

Recent randomized controlled studies have examined the efficacy of adalimumab in inflammatory bowel disease. ULTRA2 (Ulcerative colitis Long-Term Remission and maintenance with Adalimumab: treatment of moderate to severe ulcerative colitis), a 52-week randomized controlled study of patients with ulcerative colitis, showed clinical remission at week 52 in $17.3 \%$ of patients receiving adalimumab and $8.5 \%$ of patients receiving placebo $(P=0.004) .{ }^{43}$ CHARM (Crohn's trial of the fully Human antibody Adalimumab for Remission Maintenance), a 56-week randomized controlled study of patients with moderate to severe Crohn's disease, showed that at week 56 the percentage of responders in remission was significantly greater in patients that received adalimumab ( $40 \mathrm{mg}$ every other week or $40 \mathrm{mg}$ weekly) versus placebo ( $36 \%$ and $41 \%$ vs $12 \% ; P<0.001) .{ }^{44}$ Although there are reports in the literature of the successful treatment of intestinal BD using adalimumab, a randomized controlled study is yet to be undertaken.

Since intestinal BD is often refractory to conventional treatments such as colchicine, azathioprine, methotrexate, 5-ASA, and cyclosporine $\mathrm{A}$ in combination with systemic corticosteroids, alternative therapies are needed in this setting. For example, there is one case report suggesting that thalidomide in combination with infliximab is effective for the treatment of infliximab-tolerant intestinal $\mathrm{BD},{ }^{45}$ and another suggesting that mycophenolate sodium is effective for the treatment of azathioprine-tolerant intestinal BD. ${ }^{46}$

TNF- $\alpha$ blockers have also been shown to improve disease activity in patients with intestinal BD unresponsive to conventional therapies. Although infliximab has been approved in Japan for the treatment of refractory uveitis since 


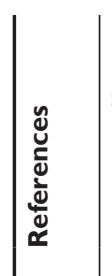

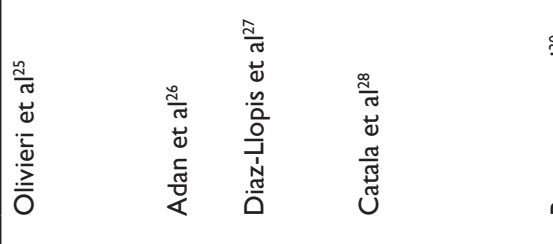

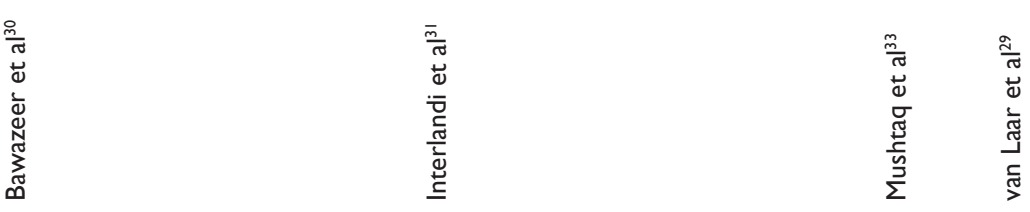

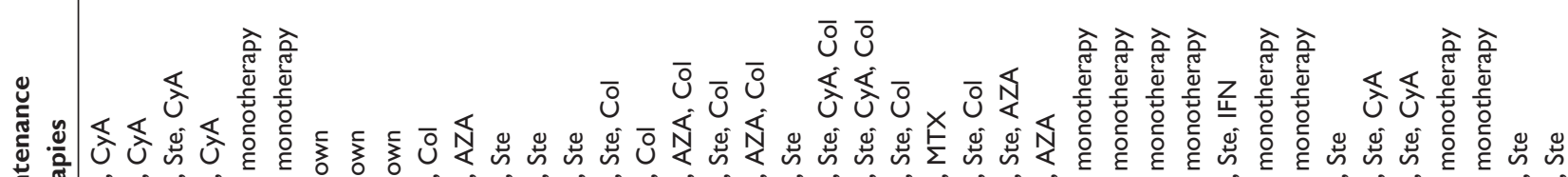

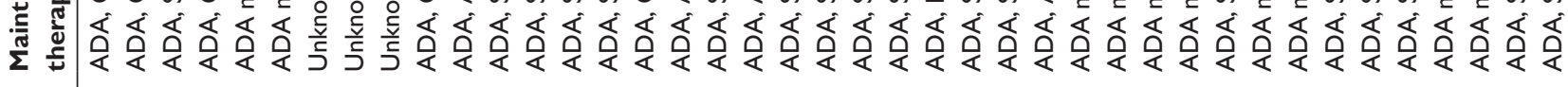

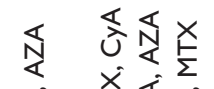

$\overline{0}$

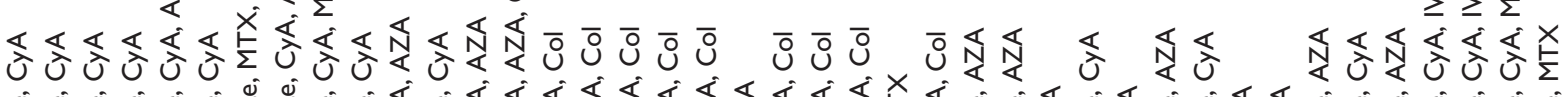

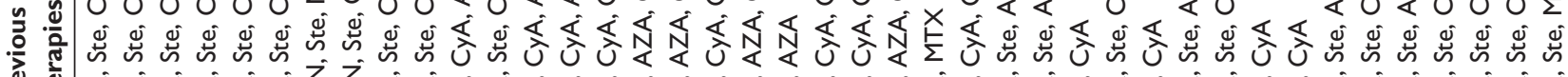

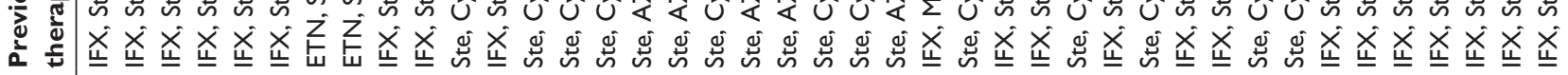
幽

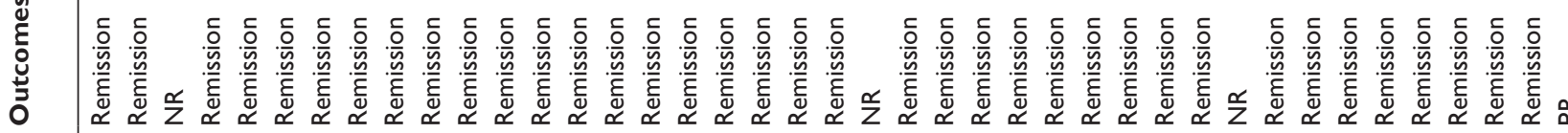

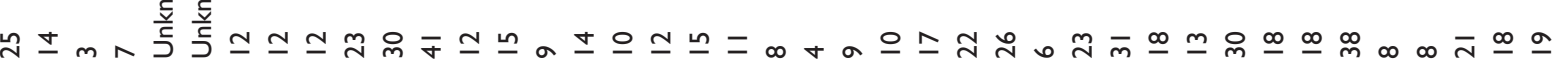
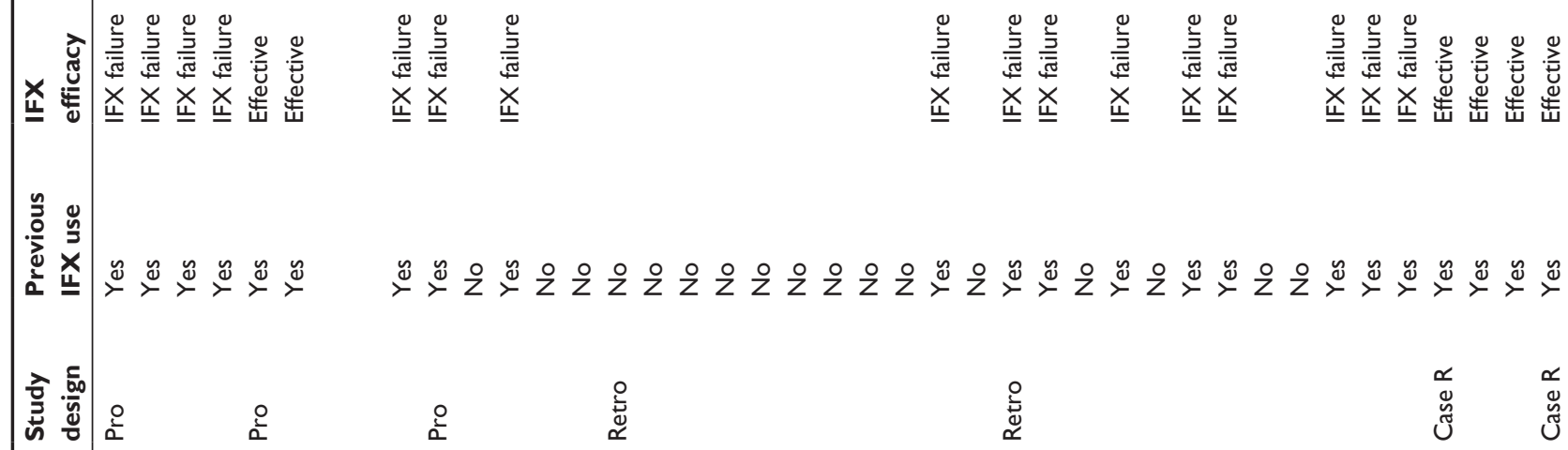

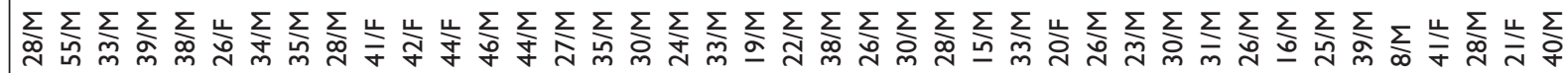

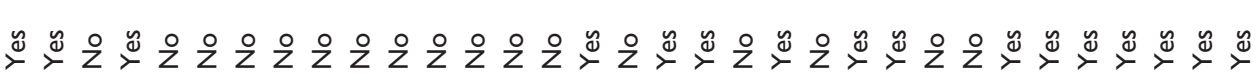<smiles>[13CH][13CH]</smiles> 


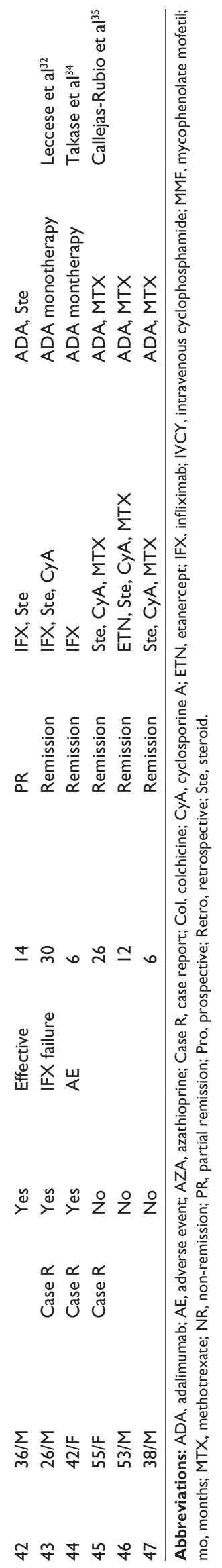

January 2007, it is yet to be approved for the treatment of refractory intestinal BD. Therefore, all the examples of the successful use of infliximab for the treatment of refractory intestinal BD have been off-label, because they did not show ocular manifestations concurrently. ${ }^{47-49}$

Kinoshita et $\mathrm{al}^{47}$ have reported 15 cases of intestinal BD treated with infliximab. After 10 weeks of treatment, 12 patients $(80 \%)$ showed response to infliximab; 8 (53\%) of these achieved remission with no intestinal symptoms and normal C-reactive protein levels. The response to infliximab was maintained in 7 of 11 patients (64\%) who were followed up at 12 months and in 4 of 8 patients (50\%) followed up at 24 months. Furthermore, Lee et a ${ }^{48}$ have reported 28 cases of intestinal BD treated with infliximab. Clinical response rates at $2,4,30$, and 54 weeks were $75.0 \%, 64.3 \%, 50.0 \%$, and $39.1 \%$, respectively, with clinical remission rates of $32.1 \%$, $28.6 \%, 46.2 \%$, and $39.1 \%$, respectively.

Although anti-TNF- $\alpha$ agents show promise for the treatment of refractory intestinal $\mathrm{BD}$, there are no data available regarding the comparative efficacies of infliximab and adalimumab in this setting. However, several case reports suggest that adalimumab may be effective (Table 2)..$^{29,50-54}$ In four case studies, the patients were initially treated with infliximab, their intestinal BD became refractory, and they were then started on adalimumab; a complete response was seen in all patients, indicating that adalimumab may be useful for patients who are intolerant to infliximab. Only one of the seven patients in the case studies listed in Table 2 showed a partial response to adalimumab; the medication was switched to infliximab and no further ulcers developed during the subsequent 6 weeks of infliximab treatment.

To clarify the safety and efficacy of adalimumab in the intestinal BD setting, a nonrandomized, open-label prospective study was recently conducted in Japanese patients with BD refractory to conventional therapies. ${ }^{55}$ Twenty BD patients with at least one ileocecal ulcer $\geq 1 \mathrm{~cm}$ in diameter and a baseline global gastrointestinal symptom score $\geq 3$ were enrolled in the study. Nine patients $(45 \%)$ showed a marked improvement in gastrointestinal symptoms at week 24, and 12 patients $(60 \%)$ showed a marked improvement at week 52. Complete remission was achieved in four patients at both weeks 24 and 52. No serious adverse events were observed by week 52 . Furthermore, adalimumab treatment was associated with the rapid resolution of extragastrointestinal BD symptoms: two-thirds of patients with oral aphthous ulcers and genital ulcers, and $88 \%$ of patients with erythema nodosum, had complete resolution of these conditions at week 52. On the basis of these findings, in May 

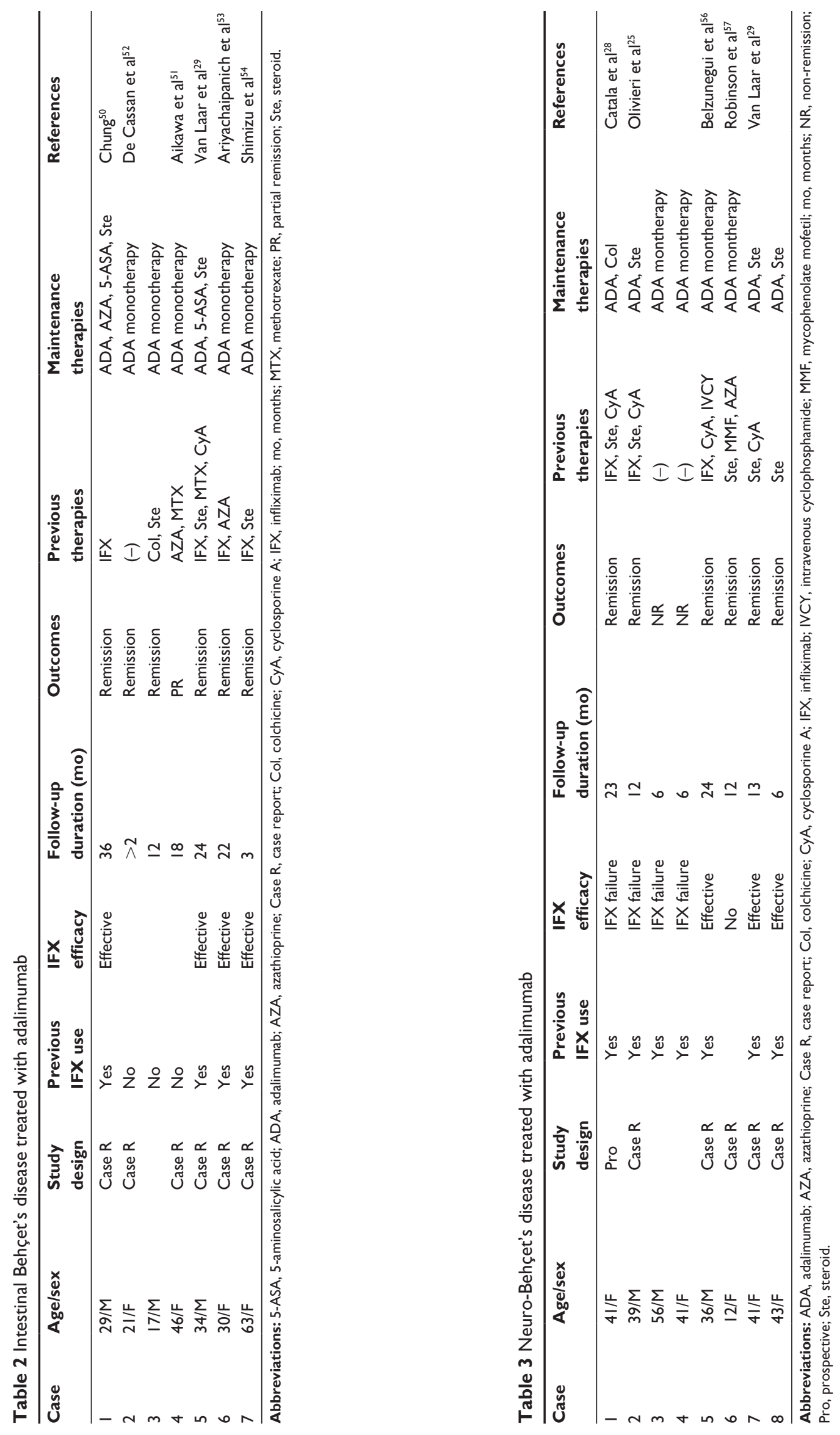
2013 adalimumab was officially approved for the treatment of intestinal BD in Japan.

\section{Adalimumab for treating BD manifestations in other organs}

In addition to a nonrandomized clinical trial showing that adalimumab is effective for the treatment of both intestinal BD and extragastrointestinal mucocutaneous lesions such as aphthosis ulcers and erythema nodosum, ${ }^{54}$ Olivieri et al have reported the clinical courses of ten cases of BD in which mucocutaneous lesions were the main clinical manifestations. ${ }^{25}$ The patients were initially treated with conventional therapy and infliximab, but after insufficient clinical efficacy or the onset of an adverse reaction to the infliximab infusion, infliximab was withdrawn and adalimumab was introduced; five patients (50\%) had complete remission, three had good responses (30\%), and two remained unchanged or their conditions worsened.

There have been no controlled studies conducted that can be used to guide the management of BD with central nervous system involvement (neuro-BD). In parenchymal neuro-BD, high-dose steroid therapy is usually followed by maintenance therapy with oral steroids and immunosuppressants. However, several cases of neuro-BD successfully treated with a TNF- $\alpha$ inhibitor have been reported. For example, eight neuro-BD patients treated with adalimumab have been reported; six achieved complete remission (Table 3). 24,27,28,56,57

Pulmonary artery aneurysm is a known complication of $\mathrm{BD}$ that is usually lethal if the aneurysm ruptures. Four cases of successful treatment of pulmonary artery aneurysm with a TNF- $\alpha$ inhibitor have been reported; three were treated with infliximab, ${ }^{58-60}$ and one with adalimumab. ${ }^{61}$

\section{Conclusion}

There is accumulating evidence that adalimumab is safe and effective for the treatment of serious manifestations of BD with sparing effects of conventional immunosuppressants and corticosteroids. Adalimumab may also be effective in patients with infliximab-refractory BD. Long-term, largescale studies are warranted to determine the efficacy and safety of adalimumab in BD patients.

\section{Disclosure}

The authors report no conflicts of interest in this work.

\section{References}

1. Ishigatsubo Y. Behçet's Disease: From Genetics to Therapies. Tokyo, Japan: Springer; 2015.

2. Al-Otaibi LM, Porter SR, Poate TW. Behçet's disease: a review. J Dent Res. 2005;84(3):209-222.
3. Mizuki N, Ota M, Yabuki K, et al. Localization of the pathogenic gene of Behçet's disease by microsatellite analysis of three different populations. Invest Opthalmol Vis Sci. 2000;41:3702-3708.

4. International Study Group for Behcet's Disease. Criteria for diagnosis of Behçet's disease. Lancet. 1990;335:1078-1080.

5. Behçet's Disease Research Committee of Japan. Behcet's disease: guide to diagnosis of Behcet's disease. Jpn J Ophthalmol. 1974;18: 291-294.

6. International Team for the Revision of the International Criteria for Behçet's Disease (ITR-ICBD), Davatchi F, Assaad-Khalil S, Calamia KT, et al. The International Criteria for Behçet's Disease (ICBD): a collaborative study of 27 countries on the sensitivity and specificity of the new criteria. J Eur Acad Dermatol Venereol. 2013; 28(3):338-347.

7. Remmers EF, Cosan F, Kirino Y, et al. Genome-wide association study identifies variants in the MHC class I, IL10, and IL23R-IL12RB2 regions associated with Behçet's disease. Nat Genet. 2010;42(8):698-702.

8. Mizuki N, Meguro A, Ota M, et al. Genome-wide association studies identify IL23R-IL12RB2 and IL10 as Behçet's disease susceptibility loci. Nat Genet. 2010;42(8):703-706.

9. Kirino Y, Bertsias G, Ishigatsubo Y, et al. Genome-wide association analysis identifies new susceptibility loci for Behçet's disease and epistasis between HLA-B*51 and ERAP1. Nat Genet. 2013;45(2):202-207.

10. Direskeneli H. Innate and adaptive responses to heat shock proteins in Behçet's disease. Genet Res Int. 2013;2013(1):1-6.

11. Tanaka T, Yamakawa N, Koike N, Suzuki J, Mizuno F, Usui M. Behçet's disease and antibody titers to various heat-shock protein 60s. Ocul Immunol Inflamm. 1999;7(2):69-74.

12. Zouboulis CC, Kötter I, Djawari D, et al. Epidemiological features of Adamantiades-Behçet's disease in Germany and in Europe. Yonsei Med J. 1997;38:411-422.

13. Misumi M, Hagiwara E, Takeno M, et al. Cytokine production profile in patients with Behçet's disease treated with infliximab. Cytokine. 2003;24(5):210-218.

14. Yamashita N, Kaneoka H, Kaneko S, et al. Role of $\gamma \delta$ T lymphocytes in the development of Behçet's disease. Clin Exp Immunol. 1997;107:241-247.

15. Kitaichi N, Miyazaki A, Iwata D, Ohno S, Stanford MR, Chams H. Ocular features of Behçet disease: an international collaborative study. Br J Ophthalmol. 2007;91(12):1579-1582.

16. Hatemi G, Silman A, Bang D, et al. EULAR recommendations for the management of Behçet disease. Ann Rheum Dis. 2008;67: $1656-1662$.

17. Okada AA, Goto H, Ohno S, Mochizuki M; for the Ocular Behçet Disease Research Group of Japan. Multicenter study of infliximab for refractory uveoretinitis in Behçet disease. Arch Ophthalmol. 2012;130:592-598.

18. Takeuchi M, Kezuka T, Sugai S, et al. Evaluation of the long-term efficacy and safety of infliximab treatment for uveitis in Behçet disease: a multicenter study Ophthalmology. 2014;121(10):1877-1884.

19. Ohno S, Nakamura S, Hori S, et al. Efficacy, safety, and pharmacokinetics of multiple administration of infliximab in Behçet's disease with refractory uveoretinitis. J Rheumatol. 2004;31:1362-1368.

20. Niccoli L, Nannini C, Benucci M, et al. Long-term efficacy of infliximab in refractory posterior uveitis of Behçet disease: a 24-month follow-up study. Rheumatology. 2007;46(7):1161-1164.

21. Giardina A, Ferrante A, Ciccia F, Vadalà M, Giardina E, Triolo G. One year study of efficacy and safety of infliximab in the treatment of patients with ocular and neurological Behçet's disease refractory to standard immunosuppressive drugs. Rheumatol Int. 2009;31(1):33-37.

22. Al-Rayes H, Al-Swailem R, Al-Balawi M, Al-Dohayan N, Al-Zaidi S, Tariq M. Safety and efficacy of infliximab therapy in active Behçet's uveitis: an open-label trial. Rheumatol Int. 2008;29(1):53-57.

23. Al-Rashidi S, Al-Fawaz A, Kangave D, Abu El-Asrar AM. Longterm clinical outcomes in patients with refractory uveitis associated with Behçet disease treated with infliximab. Ocul Immunol Inflamm. 2013;21(6):468-474. 
24. Levy-Clarke G, Jabs DA, Read RW, et al. Expert panel recommendations for the use of anti-tumor necrosis factor biologic agents in patients with ocular inflammatory disorders. Ophthalmology. 2014;121(3):785-796.

25. Olivieri I, Leccese P, D'Angelo S, et al. Efficacy of adalimumab in patients with Behçet's disease unsuccessfully treated with infliximab. Clin Exp Rheumatol. 2011;29(67):S54-S57.

26. Adán A, Hernandez V, Ortiz S, et al. Effects of infliximab in the treatment of refractory posterior uveitis of Behçet's disease after withdrawal of infusions. Int Ophthalmol. 2010;30(5):577-581.

27. Diaz-Llopis M, García-Delpech S, Salom D, et al. Adalimumab therapy for refractory uveitis: a pilot study. J Ocul Pharmacol Ther. 2008; 24(3):351-361.

28. Catalá JC, Fernandez CC, Cid AR, et al. Efficacy of adalimumab in Behçet's disease. Description of 6 cases. Rhematol Clin. 2011;7(4): 258-261.

29. van Laar JA, Missotten T, van Daele PL, Jamnitski A, Baarsma GS, van Hagen PM. Adalimumab: a new modality for Behçet's disease? Ann Rheum Dis. 2007;66(4):565-566.

30. Bawazeer A, Raffa LH. Clinical experience with adalimumab in the treatment of ocular Behçet disease. Ocul Immunol Inflamm. 2010;18(3): 226-232.

31. Interlandi E, Leccese $P$, Olivieri I, et al. Adalimumab for treatment of severe Behçet's uveitis: a retrospective long-term follow-up study. Clin Exp Rheumatol. 2014;32(84):S58-S62.

32. Leccese P, Latanza L, D'Angelo S, Padula A, Olivieri I. Efficacy of switching to adalimumab in a patient with refractory uveitis of Behçet's disease to infliximab. Clin Exp Rheumatol. 2011;29(67):S93.

33. Mushtaq B, Saeed T, Situnayake RD, Murray PI. Adalimumab for sightthreatening uveitis in Behçet's disease. Eye. 2007;21(6):824-825.

34. Takase K, Ohno S, Ideguchi H, Uchio E, Takeno M, Ishigatsubo Y. Successful switching to adalimumab in an infliximab-allergic patient with severe Behçet's disease-related uveitis. Rheumatol Int. 2011;31(2):243-245.

35. Callejas-Rubio JL, Sánchez-Cano D, Serrano JL, Ortego-Centeno N. Adalimumab therapy for refractory uveitis: a pilot study. $J$ Ocul Pharmacol Ther. 2008;24(6):613-614.

36. Frederiksen MT, Ainsworth MA, Brynskov L, Thomsen OO, Bendtzen K, Steenholdt C. Antibodies against infliximab are associated with de novo development of antibodies to adalimumab and therapeutic failure in infliximab-to-adalimumab switchers with IBD. Inflamm Bowel Dis. 2014;20:1714-1721.

37. Tunc R, Keyman E, Melikoglu M, Fresko I, Yazici H. Target organ associations in Turkish patients with Behçet's disease: a cross sectional study by exploratory factor analysis. J Rheumatol. 2002;29:2393-2396.

38. Ebert EC. Gastrointestinal manifestations of Behçet's disease. Dig Dis Sci. 2008;54(2):201-207.

39. Chen YC, Chang HW. Clinical characteristics of Behçet's disease in southern Taiwan. J Microbiol Immunol Infect. 2001;34(3):207-210.

40. Lankowski J, Crombie I, Jankowski R. Behçet's syndrome. Postgrad Med J. 1992;68:566-570.

41. Cheon JH, Han DS, Park JY, et al. Development, validation, and responsiveness of a novel disease activity index for intestinal Behçet's disease. Inflamm Bowel Dis. 2011;17(2):605-613.

42. Hisamatsu T, Ueno F, Matsumoto T, et al. The 2 nd edition of consensus statements for the diagnosis and management of intestinal Behçet's disease: indication of anti-TNF $\alpha$ monoclonal antibodies. J Gastroenterol. 2013;49(1):156-162.

43. Sandborn WJ, van Assche G, Reinisch W, et al. Adalimumab induces and maintains clinical remission in patients with moderate-to-severe ulcerative colitis. Gastroenterology. 2012;142(2):257-265.
44. Colombel JF, Schwartz DA, Sandborn WJ, et al. Adalimumab for the treatment of fistulas in patients with Crohn's disease. Gut. 2009;58: 940-948.

45. Li Y, Han Z, Wang X, et al. Combination therapy of infliximab and thalidomide for refractory entero-Behçet's disease: a case report. Gastroenterology. 2013;13(167):1-6.

46. Kappen JH, Mensink PB, Lesterhuis W, et al. Mycophenolate sodium: effective treatment for therapy-refractory intestinal Behçet's disease, evaluated with enteroscopy. Am J Gastroenterol. 2008;103(12): 3213-3214

47. Kinoshita H, Kunisaki R, Yamamoto H, et al. Efficacy of infliximab in patients with intestinal Behçet's disease refractory to conventional medication. Intern Med. 2013;52:1855-1862.

48. Lee JH, Cheon JH, Jeon SW, et al. Efficacy of infliximab in intestinal Behçet's disease: a Korean multicenter retrospective study. Inflamm Bowel Dis. 2013;19(9):1833-1838.

49. Iwata S, Saito K, Yamaoka K, et al. Efficacy of combination therapy of anti-TNF- $\alpha$ antibody infliximab and methotrexate in refractory enteroBehçet's disease. Mod Rheumatol. 2010;21(2):184-191.

50. Chung SH. Intestinal Behçet's disease appearing during treatment with adalimumab in a patient with ankylosing spondylitis. World J Gastroenterol. 2013;19(32):5389-5392.

51. Aikawa NE, Gonçalves C, Silva CA, Gonçalves C, Bonfá E, de Carvalho JF. Late response to anti-TNF- $\alpha$ therapy in refractory mucocutaneous lesions of Behçet's disease. Rheumatol Int. 2009;31(8):1097-1099.

52. De Cassan C, De Vroey B, Dussault C, Hachulla E, Buche S, Colombel J-F. Successful treatment with adalimumab in a familial case of gastrointestinal Behçet's disease. J Crohns Colitis. 2011;5(4):364-368.

53. Ariyachaipanich A, Berkelhammer C, Nicola H. Intestinal Behçet's disease: maintenance of remission with adalimumab monotherapy. Inflamm Bowel Dis. 2009;15(12):1769-1771.

54. Shimizu Y, Takeda T, Matsumoto R, et al. Clinical efficacy of adalimumab for a postoperative marginal ulcer in gastrointestinal Behçet disease. Nihon Shokakibyo Gakkai Zasshi. 2012;109(5):774-780. Japanese.

55. Tanida S, Inoue N, Kobayashi K, et al. Adalimumab for the treatment of Japanese patients with intestinal Behçet disease. Clin Gastroenterol Hepatol. 2014:1-11.

56. Belzunegui J, López L, Paniagua I, Intxausti JJ, Maíz O. Efficacy of infliximab and adalimumab in the treatment of a patient with severe neuroBehçet's disease. Clin Exp Rheumatol. 2008;26(50):S133-S134.

57. Robinson AB, Gallentine WB, Rabinovich CE. Pediatric neuro-Behçet's disease responsive to adalimumab. Pediatr Neurol. 2010;43(4): 291-293.

58. Schreiber BE, Noor N, Juli CF, Haskard DO. Resolution of Behçet's syndrome associated pulmonary arterial aneurysms with infliximab. Semin Arthritis Rheum. 2011;41(3):482-487.

59. Endo LM, Rowe SM, Romp RL, Buckmaster MA, Atkinson TP. Pulmonary aneurysms and intracardiac thrombi due to Behçet's disease in an African-American adolescent with oculocutaneous albinism. Clin Rheumatol. 2006;26(9):1537-1539.

60. Baki K, Villiger PM, Jenni D, Meyer T, Beer JH. Behçet's disease with life-threatening haemoptoe and pulmonary aneurysms: complete remission after infliximab treatment. Ann Rheum Dis. 2006;65(11): 1531-1532.

61. Lee SW, Lee SY, Kim KN, Jung JK, Chung WT. Adalimumab treatment for life threatening pulmonary artery aneurysm in Behçet disease: a case report. Clin Rheumatol. 2009;29(1):91-93. 
Therapeutics and Clinical Risk Management

Dovepress

\section{Publish your work in this journal}

Therapeutics and Clinical Risk Management is an international, peerreviewed journal of clinical therapeutics and risk management, focusing on concise rapid reporting of clinical studies in all therapeutic areas outcomes, safety, and programs for the effective, safe, and sustained use of medicines. This journal is indexed on PubMed Central, CAS,
EMBase, Scopus and the Elsevier Bibliographic databases. The manuscript management system is completely online and includes a very quick and fair peer-review system, which is all easy to use. Visit http://www.dovepress.com/testimonials.php to read real quotes from published authors.

Submit your manuscript here: http://www.dovepress.com/therapeutics-and-clinical-risk-management-journal 